\title{
Color Change in Fresh Strawberry Fruit of Seven Genotypes Stored at 0C
}

\author{
Erik J. Sacks ${ }^{1}$ and Douglas V. Shaw \\ Department of Pomology, University of California, Davis, CA 95616
}

Additional index words. Fragaria $\times$ ananassa, postharvest, red, reflectance spectrophotometry, CIELAB color scale, plant breeding

\begin{abstract}
Color change in fresh, ripe strawberry (Fragaria $\times$ ananassa Duch.) fruit stored at $0 \mathrm{C}$ for up to 7 days was recorded using the Commission Internationale de l' Éclairage color space ( $\mathrm{L}^{*}, \mathrm{a}^{*}$, and $\mathrm{b}^{*}$ ). External (skin) fruit color became darker and less chromatic but did not change hue. Internal (flesh) fruit color became darker and more chromatic. Regression coefficients calculated for individual genotypes were homogeneous for each of the color traits except internal hue. Depending on genotype, the red fruit flesh either became a bluer red or did not change hue. In all cases, rates of change were small. Color change for fresh strawberry fruit during several days of storage at $\mathrm{OC}$ likely is not an appreciable source of error in plant breeding experiments.
\end{abstract}

Although fresh ripe strawberry fruit typically darken during storage, the nature and extent of this color change has yet to be documented. Examining color change during storage with respect to genotype may identify cultivars that retain color. Moreover, understanding color change in strawberries during storage is important because plant breeders often evaluate genotypes over several days. To evaluate the importance of storage time as a potential source of error in plant breeding experiments, our study quantifiedcolor change in fresh strawberry fruit stored at $0 \mathrm{C}$.

Ripe, fully colored strawberry fruit from seven genotypes were harvested on 26 Aug. 1991 from the Univ. of California Strawberry Research Facility near Watsonville; unripe and overripe fruit were discarded. Genotypes included three cultivars with commercially acceptable color and four selections. Two selections had comparatively lighter and two had comparatively darker skin color (Fig. 1). Each genotype was represented by eight to 20 runner plants; fruit from all runner plants were pooled during harvest.

Objective measurements in the Commission Internationale de l' Éclairage (CIELAB) $\left(\mathrm{L}^{*}, \mathrm{a}^{*}\right.$, and $\left.\mathrm{b}^{*}\right)$ color space (CIE, 1978) were obtained with a Colormet reflectance spectrophotometer (Agtron, Reno, Nev.). The instrument used a D65 illuminant and a $45^{\circ} /$ normal illuminating and viewing geometry. Hue, expressed as an angular measure (h), and chroma (C*) were calculated as follows (CIE, 1978): $\mathrm{h}=\arctan \left(\mathrm{b}^{*} / \mathrm{a}^{*}\right)$ and $\mathrm{C}^{*}=\left(\mathrm{a}^{*}+\mathrm{b}^{*^{2}}\right)^{1 / 2}$. Each

Received for publication 11 June 1992. Accepted for publication 12 Nov. 1992. Research from a thesis by E.S. in partial fulfillment of the requirements of an MS in horticulture. We thank Tom Gradziel, Adel Kader, and Joe Scheerens for their editorial assistance. The cost of publishing this paper was defrayed in part by the payment of page charges. Under postal regulations, this paper therefore must be hereby marked advertisement solely to indicate this fact.

'Present address: Dept. of Vegetable Crops, Univ. of California, Davis, CA 95616. fruit was measured for external (skin) and internal (flesh) color. External color was measured on two sides of a fruit that was centered and gently pressed against the instrument's aperture. Internal color was measured likewise on two sides of a longitudinally cut fruit.

Within $1 \mathrm{~h}$ of harvest (day 0 ), the color traits of five representative fruit from each genotype were measured at the Watsonville site. The remaining fruit were transported to Davis in an air-conditioned car, then stored at OC. For the remainder of the study, color traits of a random sample of three to five fruit per
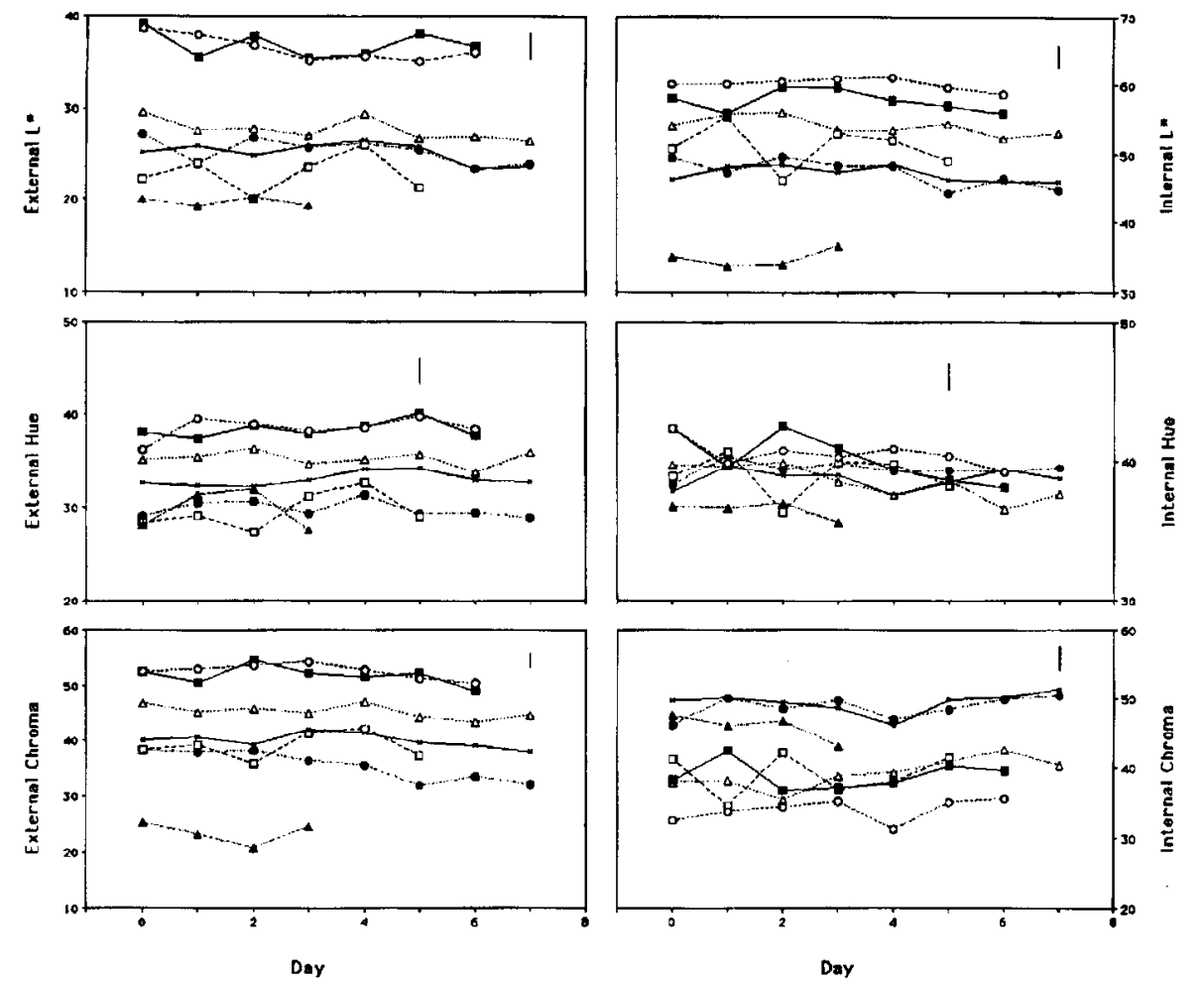

Fig. 1. Changes in color traits, over time in 0C storage, for the fruit of seven strawberry genotypes: Chandler

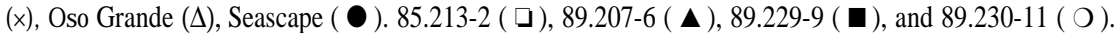
Vertical bars represent \pm SE. $0.001)$ were found among the adjusted genotypic means for the five color traits with homogeneous regression coefficients. Thus, genotypes with a broad range of initial color values maintained their at-harvest ranks for external color traits and internal $\mathrm{L}^{*}$ and $\mathrm{C}^{*}$.

Regression coefficients for external and internal $\mathrm{L}^{*}$ were small and negative (Table 2). This result indicates that the fruit darkened slowly during storage. The darkening observed in this study is consistent with the findings of a study on fresh, red raspberries (Rubus idaeus

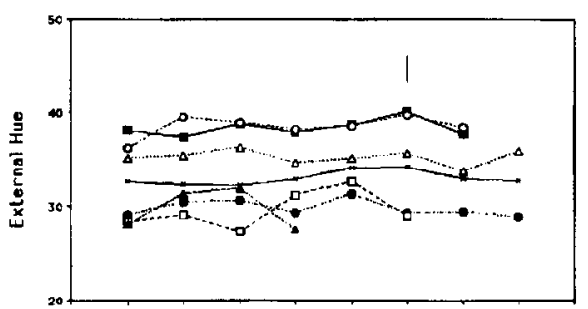

genotype per day were measured. The number of fruit available differed among genotypes, but color was assessed for at least 4 and as many as 8 days.

An analysis of covariance that tested the main effects of genotype was performed with BMDP (1981). Observations were individualfruit means. The independent variable (covariate) was the number of days in $0 \mathrm{C}$ storage. The six dependent variables were external and internal $\mathrm{L}^{*}, \mathrm{~h}$, and $\mathrm{C}^{*}$.

Graphs that represent change in color traits over time supported a linear regression model on storage time (Fig. 1). Significant differences were not detected among genotypic regression coefficients for external $\mathrm{L}^{*}, \mathrm{~h}$, and $\mathrm{C}^{*}$ and internal $\mathrm{L}^{*}$ and $\mathrm{C}^{*}$, but coefficients for internal $h$ were significantly heterogeneous $(\mathrm{P}$ $=0.026)$ (Table 1). Because regression coefficients were homogeneous, rates of change were the same for the seven genotypes in all color traits except internal $h$. Because the genotypes were chosen for their dissimilar coloration, highly significant differences $(P<$ E

\section{.}


Table 1. Tests of slope equality, among seven genotypes, for regression lines of six strawberry fruit color traits over time in $0 \mathrm{C}$ storage.

\begin{tabular}{|c|c|c|c|c|c|c|c|}
\hline \multirow[b]{3}{*}{ Source } & \multicolumn{7}{|c|}{ Mean square } \\
\hline & \multicolumn{4}{|c|}{ External } & \multicolumn{3}{|c|}{ Internal } \\
\hline & df & $\mathrm{L}^{*}$ & Hue & Chroma & $\mathrm{L}^{*}$ & Hue & Chroma \\
\hline Slope equality & 6 & $4.9^{\text {Ns }}$ & $5.5^{\mathrm{Ns}}$ & $21.1^{\mathrm{NS}}$ & $7.0^{\mathrm{NS}}$ & $10.0^{*}$ & $15.3^{\mathrm{NS}}$ \\
\hline Error & 215 & 8.3 & 8.3 & 17.5 & 11.8 & 4.1 & 14.7 \\
\hline
\end{tabular}

Ns, *Nonsignificant or significant at $P=0.05$, respectively.

L. varidaeus) (Robbins and Moore, 1990). Regression coefficients were negative for external and positive for internal $\mathrm{C}^{*}$. This result indicates that skin color became less, yet flesh color became more, chromatic with time (Table 2). Differences between external and internal $C^{*}$ may be due to differences in the concentrations or proportions of achromatic and chromatic pigments (e.g., oxidized phenolic compounds and anthocyanins, respectively) found in fruit skin and flesh. The regression coefficient for external $\mathrm{h}$ did not differ significantly from zero (Table 2). This result indicates that this trait did not change during storage.

Depending on genotype, regression coefficients for internal $h$ were either not significantly different from zero or significantly negative; the significant coefficients were -0.4 and -0.6 degrees per day for cultivar Oso Grande and selection 89.229-9, respectively. Thus, the red flesh of strawberry fruit either became a bluer red or did not change h over time, depending on genotype. Genotypic differences in the stability of internal $\mathrm{h}$ for stored, fresh fruit may be related to genotypic differences in the stability of processed strawberry h. If these two characteristics are causally related, then assessing the stability of fresh fruit internal $h$ may be a simple screen for evaluating the stability of processed fruit $h$.

Comparing color change rates (Table 2) with color trait ranges in a 1990 seedling population (Shaw, 1991) suggests that genotypes with the highest and lowest trait values are easily distinguished, even if fruit are stored and evaluated over several days. Ranges for external and internal $\mathrm{L}^{*}, \mathrm{~h}$, and $\mathrm{C}^{*}$ in this typical seedling population were as follows: 22 to 37,21 to 42,23 to 51,37 to 66,32 to 54 , and 19 to 54, respectively. For example, the difference in external $\mathrm{L}^{*}$ between fruit stored for 1 and 4 days is predicted to be $-0.81\left[\Delta \mathrm{L}^{*}\right.$ $\approx 3$ days $\times(-0.27) \mathrm{L}^{*}$ units/day] (Table 2$)$; the predicted difference is a small fraction of the range of values observed for this trait. Further, the darkening that occurs after 3 days in storage unlikely would affect visual color assessments because the smallest perceptible difference for the typical observer is about \pm 1 unit of the CIELAB scale (Instrumar Engineering, 1989). The results of this study indicate that color change for fresh strawberry fruit during
Table 2. Zero-slope tests for regression lines of five strawberry fruit color traits over time in $\mathrm{OC}$ storage.

\begin{tabular}{lccc}
\hline \hline $\begin{array}{l}\text { Dependent } \\
\text { variable }\end{array}$ & \multicolumn{4}{c}{$R$} & $\mathrm{SE}$ & \multicolumn{1}{c}{$t^{z}$} \\
\hline \multicolumn{4}{c}{ External } \\
$\mathrm{L}^{*}$ & -0.27 & 0.09 & $-2.93^{* *}$ \\
Hue & 0.10 & 0.09 & $1.04^{\mathrm{Ns}}$ \\
Chroma & -0.40 & 0.13 & $-3.02^{* *}$ \\
\multicolumn{4}{c}{ Internaly } \\
$\mathrm{L}^{*}$ & -0.31 & 0.11 & $-2.85^{* *}$ \\
Chroma & 0.25 & 0.12 & $2.05^{*}$ \\
\hline
\end{tabular}

${ }^{2}$ Values for Student's $t$ test.

'Internal hue slopes were heterogeneous and therefore not included in this test.

ss,*,**Nonsignificant or significant at $P=0.05$ or 0.01 , respectively.

several days of storage at $0 \mathrm{C}$ should not be an appreciable source of error in future plant breeding experiments.

\section{Literature Cited}

BMDP. 1981. BMDP statistical software. Univ. of California Press, Berkeley.

Commission Internationale de l' Éclairage. 1978. Recommendations on uniform color spacescolor-difference equations, psychometric color terms. Suppl. 2 to Publ. 15, Paris.

Instrumar Engineering. 1989. Colormet user's manual.

Robbins, J.A. and P.P. Moore. 1990. Color change in fresh red raspberry fruit stored at $0,4.5$, or 20C. HortScience 25:1623-1624.

Shaw, D.V. 1991. Genetic variation for objective and subjective measures of fresh fruit color in strawberries. J. Amer. Soc. Hort. Sci. 116:894898. 